удК 330.16

В. В. Артамонова

Байкальский государственный университет, 2. Иркутск, Российская Федеращия

\title{
ИСПОЛЬЗОВАНИЕ ЭЛЕМЕНТОВ ГЕЙМИФИКАЦИИ ДЛЯ ПОДДЕРЖКК ВЗАИМООТНОШЕНИЙ С КЛИЕНТАМИ В ОБЛАЧНЫХ СЕРВИСАХ
}

\begin{abstract}
АНнОтАЦИя. В условиях высокой конкуренции на рынке облачных услуг особое значение приобретает привлечение клиентов и их лояльность. Важной задачей конкурентоспособности экономических субъектов на рынке SaaS становится повышенное внимание к потребностям пользователей и разработка ряда технологий управления взаимоотношениями. Одним из новых и перспективных методов управления в этой области является геймификация как метод взаимодействия с клиентами с целью улучшения позитивных моделей использования услуг сервиса. В статье рассмотрен жизненный цикл клиентской службы облачной системы. Обозначается важность выделения и планирования этапов жизненного цикла клиентского сервиса облачной системы. Внимание уделяется анализу элементов геймификации, на основе которого была предложена их классификация. В заключении представлены положительные и отрицательные стороны использования элементов геймификации для поддержки взаимоотношений с клиентами в облачных сервисах.

кЛючЕВыЕ словА. Облачная система; сервис SaaS; жизненный цикл; клиентский сервис; геймификация.

ИНФОРМАЦИЯ О СТАТЬЕ. Дата поступления 31 июля 2017 г.; дата принятия к печати 11 октября 2017 г.; дата онлайн-размещения 25 октября 2017 г.
\end{abstract}

V. V. Artamonova Baikal State University, Irkutsk, Russian Federation

\section{USING GAMIFICATION ELEMENTS FOR SUPPORTING INTERRELATIONS WITH CLIENTS IN CLOUD SERVICES}

\begin{abstract}
In terms of high competition in the cloud service market, attracting customers and their loyalty acquires a special significance. An increased attention to the needs of users and development of a number of interrelation management technologies are becoming an important task of economic entities' competitiveness in the SaaS market. One of the new and promising management methods in this area is gamification as a method of interacting with users in order to improve the positive models of using the maintenance services. The article considers the life cycle of the client service of the cloud system. It specifies the importance of identification and planning of the life cycle stages for the client service of the cloud system. A particular attention is paid to analysis of gamification elements which serve as a basis of proposing their classification. In conclusion, the article presents the positive and negative aspects of using the gamification elements in supporting interrelation of customer in the cloud services.

KEYWORDS. Cloud system; SaaS service; lifecycle; customer service; gamification.

ARTICLE INFO. Received July 31, 2017; accepted October 11, 2017; available online October 25, 2017.
\end{abstract}

Современные условия глобализации, ускоренный обмен данными, развитие информационных технологий и новых продуктов во всех сферах деятельности позволяют говорить об уровне обработки информации как о важном факторе качественного развития практически любой экономической системы на макро- или микроуровне. Информационные технологии, являясь неотъемлемым инструментом любой организации, создают все новые инструменты достижения максимальной эффективности целей. Актуальным на сегодняшний день примером формиро-

(C) В. В. Арталонова, 2017

\section{Baikal Research Journal}


вания нового рынка на основе инновации в области информационных технологий, является возрастающая конкурентная борьба за возможность предоставления тех или иных ресурсов в качестве услуги через интернет [1, с. 51]. В специализированной литературе такие системы называются «облачными».

За последние несколько лет интерес к концепции облачных систем можно наблюдать уже не только в сфере информационных технологий, но и в предпринимательской деятельности. На рынке одной из доминирующих моделей потребления облачных услуг является «Software as a service» (далее - SaaS), то есть услуга, позволяющая не приобретать дорогое программное обеспечение, а временно использовать его.

«Главной причиной для миграции в «облако» является экономическая целесообразность. Как правило, предприятиям дешевле арендовать программное обеспечение по мере необходимости (модель «pay-as-you-go»), чем инвестировать в разработку собственной IT-инфраструктуры» [2]. Таким образом, качество обслуживания и качество предоставляемого сервиса могут стать определяющими в борьбе за место на рынке, где немаловажную роль играет такой показатель, как «коэффициент текучести клиентской базы». Основными мерами, направленными на снижение данного коэффициента, многие специалисты признают повышение и поддержание качества клиентского сервиса $[3 ; 4 ; 5]$.

Независимо от того, к какой отрасли принадлежит облачный сервис, для достижения высоких экономических результатов работы и обеспечения устойчивости к внешним факторам бизнес-среды одним из основных ресурсов становятся пользователи (клиентская база). В этих условиях особое значение приобретает вовлеченность и лояльность потребителей к продукту или услугам в рамках клиентского сервиса облачной системы. Одной из новых управленческих практик, лежащих в русле этих изменений, является геймификация клиентского сервиса как способ использования игровых элементов и программ лояльности для привлечения целевой аудитории и побуждения посетителей облачного сервиса к совершению действий.

Фундаментом для достижения требуемого качества предоставления услуг облачного сервиса является продуманный механизм управления жизненным циклом клиентского сервиса. Жизненный цикл пользователя клиентского сервиса по модели SaaS отличается от пользователя обычного программного обеспечения. Основное отличие заключается в том, что SaaS услуги предоставляются по подписке, а не на основе периодических платежей. Для того, чтобы облачной системе получить больше трафика, подписок и пользователей, необходимо понимать каждый шаг жизненного цикла клиента.

С этой целью нами были проанализированы различные источники $[1 ; 3 ; 4 ; 5$; $6 ; 7 ; 8 ; 9]$. Существует множество классификаций жизненного цикла клиента, но практически все они схожи в одном - выделении основных этапов, присущих практически любой SaaS организации: привлечение внимания покупателя, сбор информации о товаре, услуге (разведывательный этап), оценка сервиса, принятие решения, осуществление покупки, постпродажная поддержка, повторная покупка, и, как следствие, формирование лояльности клиента. Сначала потенциальный покупатель узнает о компании, знакомится подробнее с ее продуктом (через отзывы, социальные сети, рекламу), затем рассматривает целесообразность совершения соответствующей покупки, при положительном решении - приобретает продукт и становится его владельцем. Далее компания заинтересована в том, чтобы привести покупателя к повторной покупке (с помощью PR-маркетинга).

Исходя из этого, одним из первых и наиболее важных этапов разработки геймифицированной системы в рамках клиентского сервиса является понимание целевой аудитории. Не только социально-демографические характеристики могут

\section{Baikal Research Journal}

электронный научный журнал Байкальского государственного университета 
влиять на ожидания пользователя от облачного веб-сервиса, но и культурные аспекты, отношение к инновациям, социальный класс.

Для понимания мотивации пользователей облачной системы некоторые авторы отмечают необходимость создания «персонажа» [7, с. 32]. «Персонаж» - это описание лица, представляющего пользовательский сегмент клиентского сервиса «облака». Персонажи могут помочь в определении того, какой альтернативный вариант элемента геймификации в клиентском сервисе предпочтительнее, а также расставить приоритеты в привлечении пользователей.

Ричард Бартл (с англ. Richard Bartle), специалист по геймификации, разработал классификацию игроков (Bartle taxonomy of player types) [10]. Эта классификация была предназначена для описания мира игроков Warcraft, но показала себя полезной в игровом дизайне, а позже и в геймификации. Бартл провел опрос среди пользователей онлайн-игр, итогом которого стал вывод о том, что как бы ни отличались политические взгляды, хобби и привязанности пользователей игр, всех игроков условно можно поделить на четыре группы: «achievers» («карьеристы»), «explorers» («исследователи»), «socializers» («коммуникаторы») и «killers» («киллеры»).

«Карьеристы» методично добиваются поставленных целей, соревнуются не с другими пользователями, а с системой за достижения и рейтинг; «исследователей» не мотивируют достижения, очки, уровни, им нравится изучать и анализировать разные аспекты игры; «коммуникаторы» готовы оказывать помощь другим игрокам с целью расширения круга общения; «киллеры» любят участвовать в соревнованиях и показывать свое превосходство перед другими игроками. Типология Бартла во многом отражает стратегии облачных систем, применяющих в клиентском сервисе игровые технологии. Стоит отметить, что ни один человек из данной типологии не принадлежит строго к одному психотипу, а в различных ситуациях может проявлять себя по-разному.

Взяв за основу рассмотренную типологию, мы выявили взаимосвязь между содержательной составляющей игроков, ориентированной на лояльность и вовлеченность пользователей клиентского сервиса облачных систем и элементами геймификации. Таким образом, нами была предложена авторская модель классификации элементов геймификации (рис. 1).

Классификация элементов геймификации

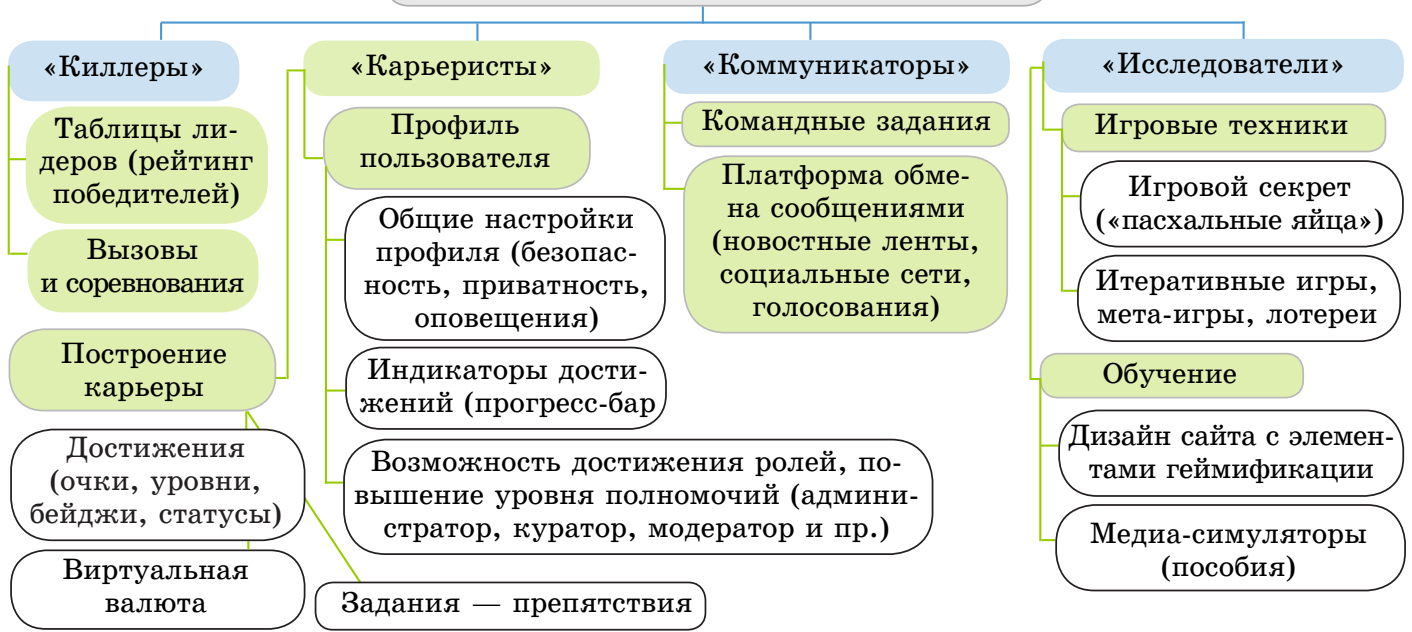

Рис. 1. Классификация әлементов гейлификации

\section{Baikal Research Journal}


Представленная классификация является универсальной и может взаимодействовать с любой базовой системой анализа и оценки деятельности на основе показателей KPI облачного сервиса. В основе ее лежит система начисления и отслеживания баллов. Каждая геймифицированная система включает в себя ряд компонентов, отвечающих за реализацию элементов геймификации. В нашей классификации мы распределили все компоненты по принципу соответствия содержательной составляющей игроков.

«Таблицы лидеров» включают в себя рейтинговую систему для пользователей с целью показать другим свои достижения. Сюда можно отнести отдельные рейтинги для мини-игр с разными игровыми механизмами, рейтинги победителей (например, «Твой результат лучше, чем у 84 \% других пользователей»).

«Вызовы и соревнования» предполагают возможность пользователям сравнивать свою әффективность и свои показатели в режиме реального времени в клиентском сервисе со средними показателями других пользователей облачного сервиса. Такое сравнение возможно организовать через миссии, сражения, битвы (например, «Битва боссов» - шанс проявить все свои знания и умения), а также разные конкурсы. Повышению эффективности и заинтересованности каждого отдельного пользователя могут способствовать задания с ограниченным количеством времени на их выполнение, в ходе которых при выигрыше, пользователь может перейти на бонусный уровень или получить некоторое вознаграждение (например, в течение определенного времени необходимо зарегистрироваться на сайте и получить возможность использовать скидки по пакетам услуг облачного сервиса: «Праздничный бонус: только сегодня при регистрации можно приобрести пакет услуг по уникальной цене со скидкой 30 \% »).

«Построение карьеры» - компонент геймификации, обеспечивающий прозрачность системы достижений в виде виртуального или материального выражения результата выполнения действий для каждого пользователя в клиентском сервисе. Наиболее универсальными элементами геймификации, отвечающими за достижения и прогресс пользователя, являются бэйджи (медали, бонусы), уровни и очки. Кевин Вербах (с англ. Kevin Werbach). и Дэн Хантер (с англ. Dan Hunter) в ходе исследований проверили более 100 вариантов внедрения геймификации, сделав вывод, что «многие системы, если не сказать большая их часть, начинаются всегда с этих трех элементов» [11, с. 12]. Например: «Вам нужно набрать 10 тысяч очков для того, чтобы перейти на пятый уровень, при этом вы откроете доступ к званию суперпользователя и новому контенту».

При разработке более серьезных геймифицированных платформ особое внимание уделяют разработке «виртуальной экономики», которая может выражаться в создании «виртуальной валюты» для приобретения товаров или услуг. Любой облачный сервис может создать свою одноименную валюту (например, «пряники», «ежики»), которую можно заработать за выполнение определенных задач: за поданные идеи, активность в клиентском сервисе, участие в конкурсах и пр.

«Профиль пользователя» - мгновенный просмотр карточек пользователей с использованием игровых механик, такие как статус, прогресс, аватар, лента событий, которые являются общими для сайтов социальных сетей. Также с помощью профиля другие пользователи могут отслеживать достижения, что является скрытой мотивацией к определенного рода действиям в рамках клиентского сервиса.

«Командные задания» и «Платформа обмена сообщениями» выполняют социальную функцию геймификации, мотивируя отдельных пользователей объединяться в команды для прохождения тех или иных заданий. Особое внимание при разработке заданий уделяется групповой психологии пользователей, основанной

\section{Baikal Research Journal}

электронный научный журнал Байкальского государственного университета 
на вирусной механике игр для привлечения новых и удержания существующих пользователей.

«Игровые техники» являются центральным компонентом системы геймификации, который запускает новые квесты и автоматически создает таблицы лидеров. Среди наиболее популярных элементов, позаимствованных из игр и успешно применяющихся в сфере геймификации, являются т. н. «пасхальные яйца» (как забавный способ вознаградить и удивить людей за их лояльность), игры без конца (в которых статическое состояние само по себе является наградой), скрытые квесты, требующие совершения неочевидных действий, и лотереи (при которых победитель выбирается случайным образом).

Платформа «Обучение» включает в себя рекомендации по следующим действиям, которые пользователя должны предпринять для достижения целей, определенных каждым квестом. Также уведомляет участников, когда они близки к достижению результатов или, когда они отстают от остальных (например, «Мы предупреждаем, что действие твоей суперсилы истекло. У тебя закончился премиум-доступ. Сейчас не самое лучшее время, чтобы забросить свои достижения. Продолжай развиваться. Мы дарим тебе скидку»).

Проанализированные нами компоненты позволяют геймифицированной системе не только повысить узнаваемость клиентского сервиса облачной

На данный момент уже накоплен позитивный опыт реализации проектов по геймификации, что привлекает все большее внимание ученых и практиков к изучению данного феномена. Но следует учитывать, что внешние вознаграждения могут также и лишить мотивации, и любой проект по внедрению элементов геймификации в клиентский сервис облачной системы должен принимать это во внимание. Иногда предоставления ряда достижений за выполнение определенных действий в клиентском сервисе может привести к тому, что пользователи будут выполнять его хуже (например, рейтинги могут полностью лишать мотивации, когда пользователь видит, насколько он далек от лидеров, то легко может оставить все попытки и выйдет из соревнования).

Действия пользователей в клиентском сервисе облачной системы зависят от мотивации и, в свою очередь, вызывают обратную связь как ответ от системы, например, в виде победных очков. Эта обратная связь, в свою очередь, мотивирует игрока совершать следующее действие и так далее. Ключевой элемент - обратная связь от облачной системы, это именно то, что делает игры эффективным мотиватором. Действия приводят к видимому ответу. Очки, к примеру, - способ отображения обратной связи об активности пользователя клиентского сервиса, как и рейтинги лидеров, уровни и бейджи. Таким образом, обратная связь вкупе с использованием элементов геймификации на разных стадия жизненного цикла клиентского сервиса облачной системы создают стимул для последующих действий $[12$, с. 46$]$.

Таким образом, все геймификационные проекты должны быть согласованы со стратегией развития организации и ценностями корпоративного бренда клиентского сервиса облачной системы [8, с. 171]. Геймификация предлагает сервисам $\mathrm{SaaS}$ широкий набор инструментов для создания эффективных систем мотивации пользователей и в ближайшие годы в этой области может стать эффективной альтернативой традиционным методам.

\section{Список использованной литературы}

1. Зараменских Е. П. Управление жизненным циклом информационных систем : монография / Е. П. Зараменских. - Новосибирск : ЦРНС, 2014. - 270 с.

\section{Baikal Research Journal}


2. Лебедев П. Обзор: Облачные сервисы 2016 / П. Лебедев. - Режим доступа: http:// www.cnews.ru/reviews/oblachnye_servisy_2016 (дата обращения: 10.08. 2017).

3. Burke B. Gamify: how gamification motivates people to do extraordinary things / B. Burke. - Brookline : Bibliomotion, 2014. - $181 \mathrm{p}$.

4. Fizek S. Rethinking gamification / S. Fizek, M. Fuchs, P. Ruffino, N. Schrape. - Lueneburg : Meson Press, 2014. - 344 p.

5. Hamari J. Transforming homo economicus into homo ludens: A field experiment on gamification in a utilitarian peer-to-peer trading service / J. Hamari // Electronic Commerce Research and Applications. - 2013. Vol. 12. - Pp. 236-245.

6. Werbach K. For the Win: How Game Thinking Can Revolutionize Your Business / K. Werbach, D. Hunter. — Philadelphia : Wharton Digital Press, 2012. — 148 p.

7. Zichermann G. Gamification by Design: Implementing Game Mechanics in Web and Mobile Apps / G. Zichermann, C. Cunningham. - Sebastopol : O’Relly Media, 2011. — 208 p.

8. Маркеева А. В. Геймификация в бизнесе: проблемы использования и перспективы развития / А. В. Маркеева // Лидерство и менеджмент. - 2015. - № 3. - С. 169-190.

9. Цыплакова Е. О. Геймификация - мотивационная практика или механизм тотального контроля над трудовым процессом? / Е. О. Цыплакова // Экономическая социология. - 2016. - № 3. - С. 82-110.

10. Bartle R. Hearts, clubs, diamonds, spades: Players who suit MUDs / R. Bartle // Journal of MUD. - 1996. - Vol. 1. - Available at: http://www.arcadetheory.org/wp-content/ uploads/2014/03/1996bartle.pdf (дата обращения: 10.08. 2017).

11. Werbach K. For the Win: How Game Thinking Can Revolutionize Your Business / K. Werbach, D. Hunter. — Philadelphia : Wharton Digital Press, 2012. — 148 p.

12. Prakash E. C. Transforming Learning and IT Management through Gamification / E. C. Prakash, M. Rao. - New York City : Springer International Publishing, 2015. $119 \mathrm{p}$.

\section{References}

1. Zaramenskikh E. P. Upravlenie zhiznennym tsiklom informatsionnykh sistem [Life cycle management for information systems]. Novosibirsk, Tsentr razvitiya nauchnogo sotrudnichestva Publ., 2014. 270 p.

2. Lebedev P. Review: cloud services 2016. Available at: http://www.cnews.ru/reviews/ oblachnye_servisy_2016.

3. Burke B. Gamify: how gamification motivates people to do extraordinary things. Brookline, Bibliomotion, 2014. $181 \mathrm{p}$.

4. Fizek S., Fuchs M, Ruffino P., Schrape N. Rethinking gamification. Lueneburg, Meson Press, 2014. 344 p.

5. Hamari J. Transforming homo economicus into homo ludens: A field experiment on gamification in a utilitarian peer-to-peer trading service. Electronic Commerce Research and Applications, 2013, vol. 12, pp. 236-245.

6. Werbach K., Hunter D. For the Win: How Game Thinking Can Revolutionize Your Business. Philadelphia, Wharton Digital Press, 2012, 148 p.

7. Zichermann G., Cunningham C. Gamification by Design: Implementing Game Mechanics in Web and Mobile Apps. O’Relly Media, 2011. 208 p.

8. Markeeva A. V. Gamification in business: problems of use and aspects of development. Liderstvo $i$ menedzhment $=$ Leadership and Management, 2015, no 3, pp. 169-190. (In Russian).

9. Tsyplakova E. O. Gamification - motivational practice or mechanism of total control over labor process? Ekonomicheskaya sotsiologiya = Economic Sociology, 2016, no. 3, pp. 82110. (In Russian).

10. Bartle R. Hearts, clubs, diamonds, spades: Players who suit MUDs. Journal of MUD, 1996 , vol. 1. Available at: http://www.arcadetheory.org/wp-content/uploads/2014/03/1996bartle.pdf

11. Werbach K., Hunter D. For the Win: How Game Thinking Can Revolutionize Your Business. Philadelphia, Wharton Digital Press, 2012. 148 p.

12. Prakash E. C., Rao M. Transforming Learning and IT Management through Gamification. New York City, Springer International Publishing, 2015. 119 p.

\section{Baikal Research Journal}

электронный научный журнал Байкальского государственного университета 


\section{Информация об авторе}

Арталонова Виктория Владилировна - аспирант, кафедра социальной и экономической психологии, социологии и социальной работы, Байкальский государственный университет, 664003, г. Иркутск, ул. Ленина, 11, e-mail: viktoria.v.artamonova@yandex.ru.

\section{Author}

Viktoria V. Artamonova - PhD Student, Chair of Social and Economic Psychology, Sociology and Social Work, Baikal State University, 11 Lenin St., 664003, Irkutsk, e-mail: viktoria.v.artamonova@yandex.ru.

\section{Для цитирования}

Артамонова В. В. Использование элементов геймификации для поддержки взаимоотношений с клиентами в облачных сервисах / В. В. Артамонова // Baikal Research Journal. 2017. — T. 8, № 3. - DOI : 10.17150/2411-6262.2017.8(3).13.

\section{For Citation}

Artamonova V. V. Using gamification elements for supporting interrelations with clients in cloud services. Baikal Research Journal, 2017, vol. 8, no. 3. DOI: 10.17150/24116262.2017.8(3).13. (In Russian).

\section{Baikal Research Journal}

